\title{
Edible bird's nest impact on rats' uterine histomorphology, expressions of genes of growth factors and proliferating cell nuclear antigen, and oxidative stress level
}

\author{
Abdulla A. Albishtue ${ }^{1,2}$, Nurhusien Yimer $^{1}$, Md Zuki A. Zakaria ${ }^{3}$, Abd Wahid Haron ${ }^{1}$, Rosnina Yusoff ${ }^{1}$, Mohammed A. Assi ${ }^{4}$ \\ and Bahaa H. Almhanawi ${ }^{5}$
}

1. Department of Veterinary Clinical Studies, Faculty of Veterinary Medicine, Universiti Putra Malaysia, 43400 Serdang, Selangor, Malaysia; 2. Department of Anatomy and Histology, Faculty of Veterinary Medicine, University of Kufa, Najaf, Iraq; 3. Department of Veterinary Preclinical Sciences, Faculty of Veterinary Medicine, Universiti Putra Malaysia, 43400 Serdang, Selangor, Malaysia; 4. Department of Community Health, College of Health and Medical Techniques, Al-Furat Al-Awsat Technical University, Iraq; 5. Department of Pathology, Faculty of Medicine and Health Sciences, Universiti Putra Malaysia, 43400 Serdang, Selangor, Malaysia.

Corresponding author: Nurhusien Yimer, e-mail: nurdeg2006@gmail.com; nurhusien@upm.edu.my

Co-authors: AAA: abdullaa.hadi@uokufa.edu.iq, MZAZ: zuki@upm.edu.my, AWH: wahidharon@gmail.com, RY: rosninanuris@upm.edu.my, MAA: razaq_assi@yahoo.com,BHA: bahaa.hemato@yahoo.com Received: 04-09-2017, Accepted: 15-12-2017, Published online: 27-01-2018

doi: 10.14202/vetworld.2018.71-79 How to cite this article: Albishtue AA, Yimer N, Zakaria MZA, Haron AW, Yusoff R, Assi MA, Almhanawi BH (2018) Edible bird's nest impact on rats' uterine histomorphology, expressions of genes of growth factors and proliferating cell nuclear antigen, and oxidative stress level, Veterinary World, 11(1): 71-79.

\begin{abstract}
Aim: This study aimed to evaluate the effect of edible bird's nest (EBN) supplementation on the uteri of rats based on analyses of the morphological and histomorphometric changes, and expressions of epidermal growth factor (EGF) and its receptor (REGF) genes, vascular endothelial growth factor (VEGF), proliferating cell nuclear antigen (PCNA), and steroid receptors.

Materials and Methods: Twenty-four Sprague Dawley rats were equally distributed into the following four groups: G1 (control), G2, G3, and G4 represented the groups treated with EBN at graded concentrations of 0, 30, 60, and 120 mg/kg body weight $(\mathrm{BW})$ per day for 8 weeks, respectively. During the experimental period, the BW of each rat was recorded weekly. At the proestrus stage of estrous cycle, blood samples were collected from the hearts of anesthetized rats that were later sacrificed. The uteri were removed for histological and immunohistochemical analyses.

Results: The EBN-treated groups showed an increase in the weights and lengths of uteri as compared to the control. Results showed that relative to G1 and G2, G3 and G4 exhibited proliferation in their uterine luminal and glandular epithelia and uterine glands, and up-regulated expressions of EGF, REGF, VEGF, PCNA, and progesterone receptor, and estrogen receptor in their uteri. The EBN increased the antioxidant $(\mathrm{AO})$ and total $\mathrm{AO}$ capacities and reduced the oxidative stress (OS) levels in non-pregnant rats.

Conclusion: Findings of this study revealed that EBN promotes proliferation of the uterine structures as evidenced by the upregulation of the expressions of steroid receptors,EGF, REGF, VEGF, and PCNA in the uterus and increased in the plasma concentrations of $\mathrm{AO}$ and reduced levels of OS.
\end{abstract}

Keywords: antioxidant, edible bird's nest, growth factors, proliferating cell nuclear antigen, uterus.

\section{Introduction}

The female reproductive tract including the uterus, ovaries, and mammary glands is all the targets of estrogen and progesterone actions [1]. The uterine effects of estrogen and progesterone are primarily executed by nuclear estrogen receptor $\left(E_{2} R\right)$ and progesterone receptor $\left(\mathrm{P}_{4} \mathrm{R}\right)$ [2]. Progesterone is essential for implantation and pregnancy maintenance in all mammals and plays a role in the proliferation, differentiation, and maintenance of endometrial stromal, glandular, and myometrial cells. Estrogen is vital for the proliferation of uterine epithelia and enhances

Copyright: Albishtue, et al. Open Access. This article is distributed under the terms of the Creative Commons Attribution 4.0 International License (http://creativecommons.org/licenses/ by/4.0/), which permits unrestricted use, distribution, and reproduction in any medium, provided you give appropriate credit to the original author(s) and the source, provide a link to the Creative Commons license, and indicate if changes were made. The Creative Commons Public Domain Dedication waiver (http:// creativecommons.org/publicdomain/zero/1.0/) applies to the data made available in this article, unless otherwise stated. the progesterone action by inducing the PR gene. Low estrogen levels in women have been associated with elevated rates of menstrual dysfunction, such as amenorrhea and irregular menstruation [3]. A study on cognitive aging by researchers from Universiti Putra Malaysia (UPM) has recently reported an increased serum estradiol level found in ovariectomized rats fed with edible bird's nest (EBN) dietary supplement. Hence, the scholars concluded that EBN can be used as estrogen therapy for ovariectomized-induced, aging-related memory loss [4]. Such work reinforced the findings of previous studies that EBN contains estradiol. Matsukawa et al. [5] studied the effect of dietary EBN extract against osteoporosis in ovariectomized rats and also observed that the serum estradiol levels in ovariectomized rats were similar to those in non-ovariectomized rats. This result reflected the compensatory role of the EBN extract for estrogen $\left(E_{2}\right)$ in the absence of the ovary and may benefit postmenopausal women with high osteoporosis risk. 
The EBN possesses other biological properties that may potentially influence mammalian reproduction and fertility. These properties include its high sialic acid content [6], epidermal growth factor (EGF)-like activity [7], and a stimulatory effect on cell growth and regeneration $[8,9]$. Emerging research findings on EBN in areas other than reproduction have shown that EBN enhances the production of reproductive hormones, such as estrogen, and serves as an antioxidant (AO). Sialic acid constitutes the greatest proportion of sugar in EBN and is an important molecule found in all animal cells. This compound plays several biological roles, such as in cell communication and as a signaling molecule [10]. Sen et al. [11] described the estradiol-mediated regulating role of sialic acid in the binding protein expression in human endometrium.

The present study aimed to investigate the role of in vivo supplementation of EBN in female reproduction using a rat model. We fed EBN extracts to rats at different concentrations, conducted gross and histomorphometric analyses of reproductive tissues, and determined the reproductive parameters and associated biomarkers. We also detected the expression of genes and their receptors (EGF and receptor of epidermal growth factor [REGF], vascular endothelial growth factor [VEGF], and proliferating cell nuclear antigen [PCNA]) and assessed their degree of protection against oxidative stress (OS) damage by standard techniques.

\section{Materials and Methods}

Ethical approval

All procedures performed according to Institutional Animal Care and Use Committee guideline, UPM (Project approval number: UPM/IACUC/ AUPR009/2016).

\section{EBN preparation}

EBN was purchased from Nest Excel Resources Sdn Bhd and maintained at $25^{\circ} \mathrm{C}-30^{\circ} \mathrm{C}$. EBN extract was prepared in accordance with the Chinese tradition as indicated by the local EBN suppliers. The samples were cleaned, dried at room temperature, and ground into powder using a mixer (BUCHI-400, Switzerland). The ground EBN extract was maintained at $4^{\circ} \mathrm{C}$. EBN solution was prepared by dissolving $1 \mathrm{~g}$ of EBN powder in $100 \mathrm{~mL}$ of distilled water (DW), followed by heating in a water bath at $60^{\circ} \mathrm{C}$ for $45 \mathrm{~min}$. Finally, the EBN solution was cooled down to room temperature and administered to the rats at doses based on their body weights (BWs).

\section{Animals and experimental design}

This study embodied a $24(6 \times 4$ groups $)$ adult female Sprague Dawley rats from the Animal Resource Center, Faculty of Veterinary Medicine, UPM. The rats were housed in cages in groups for an acclimation period of 7 days with free access to water and standard rat diet (Gold Coin Brand Animal Feed, Malaysia). After 7 days period of acclimation, the animals were categorized into four groups and supplemented with EBN solution on the basis of Table-1 for 8 weeks. All the groups were under free access to water. The determination of EBN dose was based on a previous report as described by Ismail et al. [4]. During the administration period, the rat BWs in each group were measured and recorded every week. At the proestrus stage, the rats were euthanized at stipulated dates ( 8 weeks) by $\mathrm{CO}_{2}$ asphyxiation method following a general anesthesia procedure, which included administration of $30 \mathrm{mg}$ ketamine $/ \mathrm{kg} \mathrm{BW}$ and $10 \mathrm{mg}$ xylazine $/ \mathrm{kg} \mathrm{BW}$ for blood collection.

\section{Determination of estrous cycle phases and synchronization}

Every day during the experimental period, vaginal smears were obtained in the morning at 09:0010:00 h using wooden swab sticks with cotton tips. The tips were then moistened by dipping into the distilled water and then inserted carefully into the vagina to about $1.0 \mathrm{~cm}$. The swab was subsequently smeared onto a sterile microscopic slide $(75 \mathrm{~mm} \times 25 \mathrm{~mm})$ through a rotatory movement of the tip. The slide was fixed with methanol and stained with 5\% Giemsa stain for 3 min and then observed under a light microscope (Leitz Laborlux-S, Wetzlar, Germany) with 40× objective lenses to determine the percentage of cells in the vaginal smear. The rats were synchronized for estrus using two intraperitoneal doses of $0.5 \mathrm{mg}$ of cloprostenol 3 days apart [12].

\section{Macroscopic and microscopic examinations of the reproductive tract and liver}

After sacrificing the anesthetized rats, their liver and uterus were excised, weighed, and measured in length. Any evident abnormality found during gross examination was recorded. The histology samples were fixed in $10 \%$ formalin for $24 \mathrm{~h}$, sectioned, and stained using hematoxylin and eosin $(\mathrm{H} \& \mathrm{E})$. The samples were observed under a microscope for histological changes, including those in the endothelial lining and the number of uterine glands [13]. Sections were cut from the central region to the peripheral region. The thicknesses of the luminal epithelium (LE), glandular epithelium (GE), and endothelium, and the number of uterine glands were determined using the Medical Image Analysis software (Motic Image plus 2.0, China).

Analyses of the expression of EGF, REGF, PCNA, VEGF, $E_{2} R$, and $P_{4} R$ in uterine tissues by immunohistochemistry

The protein expression was investigated by immunohistochemistry. Samples were sliced $(4 \mu \mathrm{m}$ thickness), deparaffinized, and dehydrated. Antigens were retrieved by incubating the specimens in 0.01 $\mathrm{M}$ citrate buffer $(\mathrm{pH} 6.0)$ at $80^{\circ} \mathrm{C}$ for $10 \mathrm{~min}$, cooling naturally to RT. Specimens were rinsed for $1 \mathrm{~min}$ in Tris-buffered saline (TBS), marked with a Daco pen (Dako, Glostrup, Denmark). Excess wash buffer was removed by tapping. Peroxidase block solution 
Table-1: Animal grouping and treatment regime of EBN administered by gavage needle.

\begin{tabular}{lll}
\hline Group & Group assigned & Type of feed (dose) \\
\hline Control & G1 (No dose) & ND+Normal saline (1 mL) \\
Treated & G2 (Low dose) & ND+EBN (30 mg/kg body weight) \\
& G3 (Medium dose) & ND+EBN (60 mg/kg body weight) \\
& G4 (High dose) & ND+EBN (120 mg/kg body weight) \\
\hline
\end{tabular}

$\mathrm{EBN}=$ Edible bird's nest, ND=Normal diet

(Animal Research Kit, Daco, North America) was applied to cover the specimen, which was incubated for $10 \mathrm{~min}$ at $37^{\circ} \mathrm{C}$ and rinsed with PBS or TBS. The specimens were incubated with rabbit anti-ER $(1: 200)$, rabbit anti-PR $(1: 100)$, rabbit anti-EGF $(1: 100)$, or rabbit anti-REGF (1:500) in TBS for $40 \mathrm{~min}$ at $37^{\circ} \mathrm{C}$. A section was prepared without the primary antibodies (replaced with PBS) to serve as the negative control. The specimens were washed with TBS and incubated at $37^{\circ} \mathrm{C}$ with biotin-labeled secondary antibody (Envision+System-HRP Labeled Polymer Anti-Rabbit, Daco, North America) for $40 \mathrm{~min}$ or mouse anti-PCNA antibody PC-10 (Dako, Glostrup, Denmark) or mouse VEGF antibody (Abcam, USA) in PBS for $20 \mathrm{~min}$. Tissue sections were incubated with streptavidin-peroxidase (Animal Research Kit, Daco, North America) for $20 \mathrm{~min}$ at $37^{\circ} \mathrm{C}$. Chromogenic reaction was conducted with $\mathrm{DAB}$ for 3-10 min and terminated by rinsing with water. Finally, the sections were counterstained with hematoxylin and were mounted. Yellowish-brown color was considered positive staining, and staining density was scored from 0 to $+3(0$ : none, +1 : mild, +2 : medium, and +3 : severe) [14]. Five sections per sample and five fields per section were randomly selected for analysis using the Medical Image Analysis software (Motic Image plus 2.0, China).

\section{OS biomarker (OSB) and AO assay}

Plasma samples were also obtained to analyze for OSBs (such as thiobarbituric acid reactive substance [TBARS] and a marker of lipid peroxidation) and AOs (such as superoxide dismutase [SOD] activity and total AO capacity [TAC]), as described by Schmidt et al. [15] and El Yew et al. [16]. The extent of lipid peroxidation in the plasma was assessed by measuring the TBARS by the TBARS assay kit (QuantiChrome ${ }^{\mathrm{TM}}$ a TBARS Assay Kit, Bioassay system, San Francisco Bay Area, USA). The SOD activity was determined in the plasma and tissue homogenates using the Enzychrom ${ }^{\mathrm{TM}}$ superoxide Dismutase Assay Kit (Bioassay System, San Francisco Bay Area, USA), which assesses the percentage of superoxide radicals that undergoes dismutation in a given sample [15]. The TAC was quantified by a commercially available kit (QuantiChrome ${ }^{\mathrm{TM}}$ AO Assay Kit, Bioassay System, San Francisco Bay Area, USA) that measures the oxidation of 2,29-azino-di-3-ethybenzthiazoline sulfonate by metmyoglobin, which is inhibited by non-enzymatic AOs contained in the sample.

\section{Statistical analysis}

All results were expressed as means \pm standard error of the mean and analyzed with GraphPad Prism 6.0 (GraphPad Software, San Diego, California). Analysis of variance (ANOVA) with Tukey multiple comparison post hoc tests was used to compare the ovarian and uterine BW ratios and lengths; thicknesses of the LE, GE, and endothelium; numbers of uterine glands; levels of hormones, OSBs, and AOs; and expression levels of steroid receptors, growth factors, and PCNA, and steroid receptors; and the concentrations of hormones, OSB, and AO. Meanwhile, two-way ANOVA with Bonferroni's multiple comparison tests was employed to compare the BWs.

\section{Results}

Representative photomicrographs of estrous cycle stages revealed the changes in the proportion of the vaginal cells at each stage. The rats had normal estrous cycle duration (4 days). Three cell types were observed in the vaginal smears. The relative ratios of these cells can be used to identify the estrous cycle stage of the rat on the day of sample collection. Clusters of round nucleated epithelial cells with individual lightly stained cytoplasms and oval nuclei were noted during the proestrus stage (Figure-1A, white arrow). Packed clusters of cornified squamous epithelial cells were observed during the estrus stage (Figure-1B, black arrow). Polymorphonuclear leukocytes and few cornified epithelial cells were apparent during the metestrus stage (Figure-1C). In the diestrus stage, leukocytes predominated, and the number of both cornified and nucleated epithelial cells was reduced (Figure-1D).

The uterine -to-BW ratios and lengths were significantly increased in the treatment groups and attained the highest value $(p<0.05)$ in G4 (Figure-2). Uterine weights and lengths increased dose-dependently with EBN. The rat uteri were assessed in the proestrus stage. The uterine histomorphometric data from all the groups are showed in Figure-3. The thicknesses of LE, GE, and endometrium were increased dose-dependently with EBN. All treated groups achieved significantly $(p<0.05)$ higher thicknesses of LE, GE, and endothelium than the control (Figure-3A-C). The highest number of uterine glands was observed in $\mathrm{G} 4(\mathrm{p}<0.05)$ and was significantly higher than that in G1, while that in G3 was comparable to those in G2 and G4. The uterine glands and GE thickness significantly increased dose-dependently in 
G4 $(\mathrm{p}<0.05)$ with respect to that in the control. The results in G2 and G3 were insignificantly lower than that in G4 but higher than that in the control (G1).

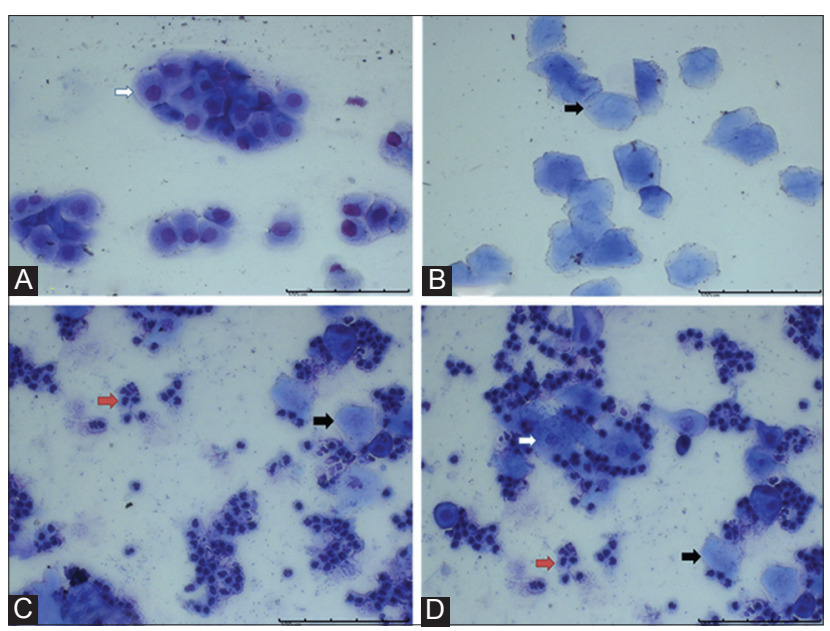

Figure-1: Stages of the estrous cycle in the rat as monitored by vaginal cytology. Nucleated epithelial cells (white arrow), cornified squamous epithelial cells (black arrow), and leukocytes (red arrow). (A) Pro estrus. (B) Estrus. (C) Met estrus. (D) Di estrus.
Figure-4 shows representative histological sections of the liver of the four experimental groups. The microscopic examination of the liver showed no pathological lesions were in any part of the liver in all groups.

\section{Expression of EGF, REGF, PCNA, and VEGF in the} uterus

Representative immunohistochemical photomicrographs showing the expressions of EGF, PCNA, and VEGF in the histological uterine sections of all the experimental groups are displayed in Figure-5, whereas the respective score differences are listed in Table-2. The increasing EBN dose also increased the density of stromal cells and the expression levels of EGF, REGF, PCNA, and VEGF in the uterine LE and GE. Consequently, the expression increment in all the above parameters was found significant under the highest EBN dose $(\mathrm{G} 4)$ with respect to those in the control and other treated groups $(\mathrm{p}<0.05)$ (Table-2). G3 achieved the second highest expression of EGF, REGF, PCNA, and VEGF. The levels were significantly higher than those in the control and G2 (Table-2).

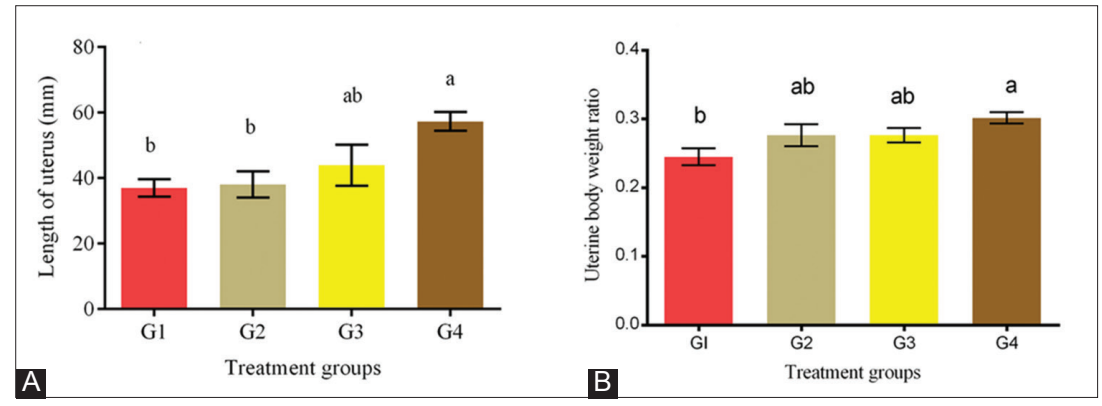

Figure-2: (A-B) Effect of edible bird's nest (EBN) on uterine to body weight ratio and length change of non-pregnant rats. Data are expressed as means \pm standard error. Different letters $a, b$, and $c$ within rows denotes significant difference at $\mathrm{p}<0.05$. Notice, $\mathrm{G} 1=$ Control; $\mathrm{G} 2=\mathrm{EBN}$ ( $30 \mathrm{mg} / \mathrm{kg}$ body weight); $\mathrm{G} 3=\mathrm{EBN}$ ( $60 \mathrm{mg} / \mathrm{kg}$ body weight); G4=EBN (120 mg/kg body weight).

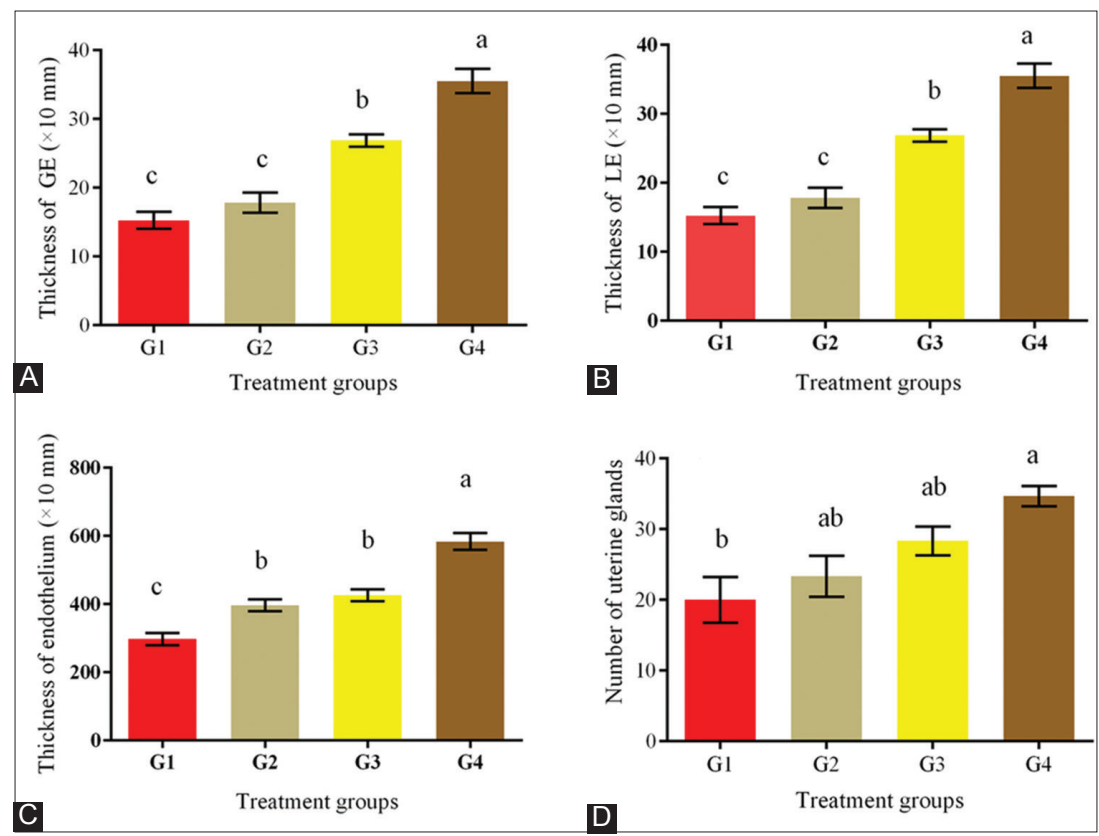

Figure-3: (A-D) Histomorphometric parameters evaluated in the rat uterus, measured during the proestrus phase. $\mu \mathrm{m}$ : micrometer. Data are expressed as means \pm standard error. Different letters $a, b$, and $c$ within rows denotes significant difference at $\mathrm{p}<0.01$. 
Table-2: Expressions of EGF, REGF, VEGF, and PCNA in the $L E, G E$, and stromal cells of uteri of rats treated with different doses of EBN and sacrificed at proestrus stage of the estrous cycle.

\begin{tabular}{lcccc}
\hline Parameter & \multicolumn{4}{c}{$\begin{array}{c}\text { Expression level } \\
\text { (mean } \pm \text { standard error) }\end{array}$} \\
\cline { 2 - 5 } & $\mathbf{G 1}$ & $\mathbf{G 2}$ & $\mathbf{G 3}$ & $\mathbf{G 4}$ \\
\hline EGF in LE & $1.5 \pm 0.3^{\mathrm{d}}$ & $2.0 \pm 0.1^{\mathrm{c}}$ & $2.5 \pm 0.3^{\mathrm{b}}$ & $3.0 \pm 0.0^{\mathrm{a}}$ \\
EGF in GE & $2.0 \pm 0.0^{\mathrm{c}}$ & $2.5 \pm 0.0^{\mathrm{b}}$ & $3.0 \pm 0.0^{\mathrm{a}}$ & $3.0 \pm 0.0^{\mathrm{a}}$ \\
EGF in S & $1.5 \pm 0.0^{\mathrm{d}}$ & $2.0 \pm 0.0^{\mathrm{c}}$ & $2.5 \pm 0.0^{\mathrm{b}}$ & $3.0 \pm 0.0^{\mathrm{a}}$ \\
REGF in LE & 0 & 0 & $0.5 \pm 0.0^{\mathrm{b}}$ & $1.5 \pm 0.0^{\mathrm{a}}$ \\
REGF in GE & 0 & 0 & $0.5 \pm 0.0^{\mathrm{b}}$ & $1.5 \pm 0.0^{\mathrm{a}}$ \\
REGF in S & 0 & 0 & $1.0 \pm 0.0^{\mathrm{b}}$ & $2.5 \pm 0.0^{\mathrm{a}}$ \\
VEGF in LE & $1.0 \pm 0.0^{\mathrm{d}}$ & $1.5 \pm 0.0^{\mathrm{c}}$ & $2.0 \pm 0.0^{\mathrm{b}}$ & $2.5 \pm 0.0^{\mathrm{a}}$ \\
VEGF in GE & $1.5 \pm 0.0^{\mathrm{c}}$ & $1.5 \pm 0.0^{\mathrm{c}}$ & $2.0 \pm 0.0^{\mathrm{b}}$ & $3.0 \pm 0.0^{\mathrm{a}}$ \\
VEGF in S & $1 . \pm 0.0^{\mathrm{c}}$ & $1.5 \pm 0.0^{\mathrm{b}}$ & $1.5 \pm 0.0^{\mathrm{b}}$ & $2.5 \pm 0.0^{\mathrm{a}}$ \\
PCNA in LE & 0 & $1.0 \pm 0.0^{\mathrm{b}}$ & $2.0 \pm 0.0^{\mathrm{b}}$ & $3.0 \pm 0.0^{\mathrm{a}}$ \\
PCNA in GE & 0 & $1.5 \pm 0.0^{\mathrm{c}}$ & $2.0 \pm 0.0^{\mathrm{b}}$ & $3.0 \pm 0.0^{\mathrm{a}}$ \\
PCNA in S & 0 & $1.0 \pm 0.0^{\mathrm{c}}$ & $1.5 \pm 0.0^{\mathrm{b}}$ & $2.5 \pm 0.0^{\mathrm{a}}$ \\
\hline LE L & 0 &
\end{tabular}

LE=Luminal epithelium, GE=Glandular epithelium, $\mathrm{S}=$ Stromal cells. Data are expressed as means \pm standard error. Different letters $a, b$, and $c$ denotes significant difference at $\mathrm{P}<0.05$. NC $=$ Control without antibody. G1 $=$ Control, G2 $=\mathrm{EBN}(30 \mathrm{mg} /$ $\mathrm{kg}$ body weight); $\mathrm{G} 3=\mathrm{EBN}$ ( $60 \mathrm{mg} / \mathrm{kg}$ body weight); $\mathrm{G} 4=\mathrm{EBN}$ (120 mg/kg body weight); EGF=Epidermal growth factor, REGF=Receptor of epidermal growth factor, VEGF=Vascular endothelial growth factor, $\mathrm{PCNA}=$ Proliferating cell nuclear antigen, $\mathrm{EBN}=$ Edible bird's nest
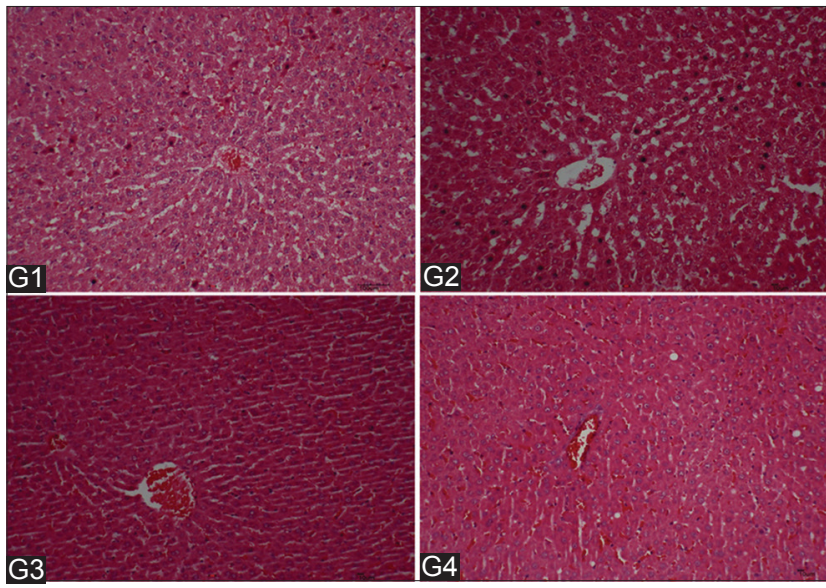

Figure-4: Photomicrograph reveals that histological structures of rat liver at the $8^{\text {th }}$ week after treatment of rats with different dosages of edible bird's nest (EBN). $\mathrm{G} 1=$ Control; $\mathrm{G} 2=\mathrm{EBN}$ (30 mg/kg body weight); G3=EBN (60 mg/kg body weight); G4=EBN (120 mg/kg body weight).

\section{Expression of steroid receptors $\left(E_{2} R\right.$ and $\left.P_{4} R\right)$ in uterine tissues}

Representative immunohistochemical photomicrographs revealing the expressions of receptors of estradiol $\left(E_{2} R\right)$ and progesterone $\left(P_{4} R\right)$ in the uterine histological sections of all the experimental groups are shown in Figure-6, whereas the respective score differences are listed in Table-3. No staining was noted for the $\mathrm{E}_{2} \mathrm{R}$ in the $\mathrm{G} 1, \mathrm{G} 2$, and $\mathrm{G} 3$ samples, except for the staining in the uterine gland and uterine surface epithelium in G3. By contrast, G4 attained the highest $E_{2} R$ expression $(p<0.05)$ (Figure-6 and Table-3).
The stromal cell density and the $\mathrm{P}_{4} \mathrm{R}$ expression in the USE and uterine gland epithelium increased with the increasing EBN dose. The rats with the highest EBN dose (G4) showed a significant increase in all the above parameters relative to those of the control and the other treated groups $(\mathrm{p}<0.05)$ (Table-3). G3 exhibited the second highest $\mathrm{P}_{4} \mathrm{R}$ expression, which was also significantly higher than those of the control and G2 (Table-3).

\section{OSB and AO assay}

In this study, the TBARS levels, TACs, and SOD activities in the plasma from all the groups are shown in Figure-7. The decrease in TBARS level and increase in SOD activity in the treatment groups were both dose-dependent. These effects changed the redox status by enhancing the enzymatic AO defense (SOD) and increasing the TAC. These results indicated that EBN modifies and attenuates the redox system.

\section{Discussion}

There has been an increase in interest in natural substances and their bioactive components in the past two decades. One of the primary motives was hormone replacement therapy that showed their dangerous side effects over time, whereas natural substances have generally centuries-long use without side effects [17]. According to a recent study, the estrous cycle is a regular progression affected by the release of gonadotropin-releasing hormone from the hypothalamus, gonadotropins from the pituitary gland, and sex hormones from the gonads. EBN also possesses estrogenic activity and increases the number of uterine glands $[4,13]$. The present results revealed that the rat BWs increased due to EBN nutritional value. According to Sen et al. [11], the expression of the sialic acid binding protein in human endometria is regulated by estradiol. In this study, uterine weight and length significantly increased in the treatment groups with respect to those in control. This result confirmed the correlation of the estrogen and sialic acid content of EBN to the weight and length of the uterus. In this study, histological examination of the uteri of the different treatment groups revealed EBN-induced dose-dependent changes, which were characterized by thickening of LE, GE, and endometrium and the increase in uterine gland numbers. The endometrial glands and their secretions are important in maintaining estrous cycles, conceptus survival, and growth at the peri-implantation stage [18]. Therefore, EBN enhances the utero physiological functions by maintaining uterine glandular secretions, such as growth factors, hormones, and transport proteins, and for conceptus embryogenesis [11]. In previous studies, serum toxicity markers (alkaline phosphatase, alanine transaminase, urea, and creatinine) did not change [4]. This result agrees with the lack of apparent gross pathological and histological lesions observed in any of the vital organs, including the liver in the present study. Instead, EBN 
Table-3: Expressions of $E_{2} R$ and $P_{4} R$ in the $L E, G E$ and stromal cells of uterus of rats treated with different doses of EBN and sacrificed at proestrus stage of the estrous cycle.

\begin{tabular}{lccccc}
\hline Parameter & \multicolumn{4}{c}{ Expression level (Mean \pm SE) } \\
\cline { 2 - 6 } & NC & G1 & G2 & G3 & G4 \\
\hline$E_{2} R$ in LE & 0 & 0 & 0 & $1.0 \pm 0.0^{\mathrm{b}}$ & $3.0 \pm 0.0^{\mathrm{a}}$ \\
$\mathrm{E}_{2} \mathrm{R}$ in GE & 0 & 0 & 0 & $1.0 \pm 0.0^{\mathrm{b}}$ & $3.0 \pm 0.0^{\mathrm{a}}$ \\
$\mathrm{E}_{2} \mathrm{R}$ in S & 0 & 0 & 0 & $2.5 \pm 0.0^{\mathrm{b}}$ & $3.0 \pm 0.0^{\mathrm{a}}$ \\
$\mathrm{P}_{4} \mathrm{R}$ in LE & $0.25 \pm 0.00^{\mathrm{d}}$ & $1.5 \pm 0.0^{\mathrm{d}}$ & $2.0 \pm 0.0^{\mathrm{c}}$ & $2.5 \pm 0.0^{\mathrm{b}}$ & $3.0 \pm 0.0^{\mathrm{a}}$ \\
$\mathrm{P}_{4} \mathrm{R}$ in GE & $0.25 \pm 0.0^{\mathrm{d}}$ & $1.5 \pm 0.0^{\mathrm{d}}$ & $2.0 \pm 0.0^{\mathrm{c}}$ & $2.5 \pm 0.0^{\mathrm{b}}$ & $3.0 \pm 0.0^{\mathrm{a}}$ \\
$\mathrm{P}_{4} \mathrm{R}$ in S & $0.25 \pm 0.00^{\mathrm{d}}$ & $1.5 \pm 0.0^{\mathrm{d}}$ & $2.0 \pm 0.0^{\mathrm{c}}$ & $2.5 \pm 0.0^{\mathrm{b}}$ & $3.0 \pm 0.0^{\mathrm{a}}$ \\
\hline
\end{tabular}

$\mathrm{LE}=$ Luminal epithelium; $\mathrm{GE}=$ Glandular epithelium, $\mathrm{S}=$ stromal cells. Data are expressed as means $\pm \mathrm{SE}$. Different letters $\mathrm{a}, \mathrm{b}$, and $\mathrm{c}$ denotes significant difference at $\mathrm{P}<0.05$. NC=Control without antibody. $\mathrm{G} 1=$ Control; $\mathrm{G} 2=\mathrm{EBN}$ ( $30 \mathrm{mg} / \mathrm{kg}$ body weight); $G 3=E B N\left(60 \mathrm{mg} / \mathrm{kg}\right.$ body weight); $G 4=E B N\left(120 \mathrm{mg} / \mathrm{kg}\right.$ body weight). $E_{2} R=$ Nuclear estrogen, $P_{4} R=N u c l e a r$ progesterone, $\mathrm{SE}=$ Standard error, $\mathrm{EBN}=$ Edible bird's nest
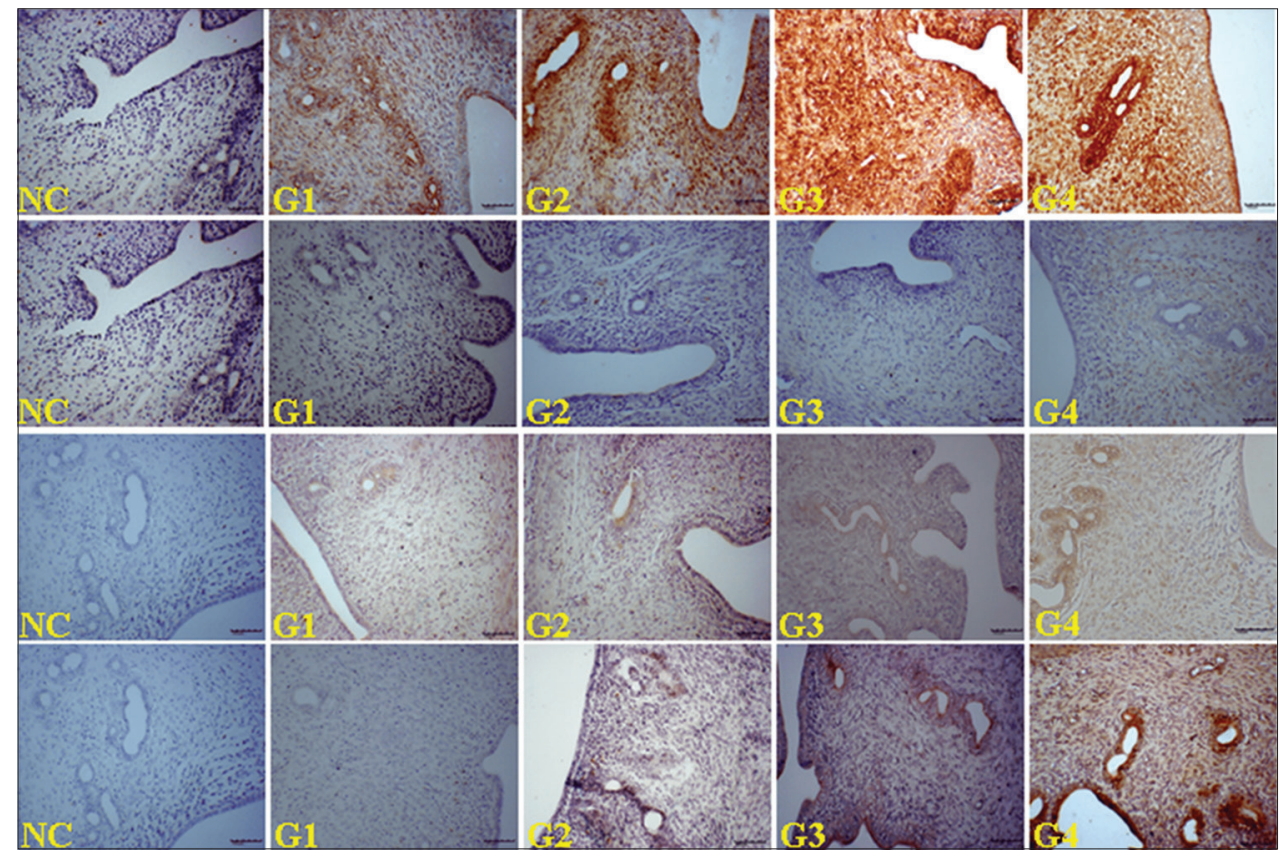

Figure-5: Photomicrograph sections of the uteri of rats of different experimental groups (G1, G2, G3, and G4) treated with different doses of edible bird's nest (EBN) showing expressions of epidermal growth factor (EGF), vascular endothelial growth factor (VEGF), and proliferating cell nuclear antigen (PCNA), respectively $(200 \times)$. Photomicrographs labeled with negative control (NC) represents control stains without antibody and immunity reaction for EGF ( $1^{\text {st }}$ row), REGF ( $2^{\text {nd }}$ row), VEGF ( $3^{\text {rd }}$ row), and PCNA (4rd row) groups, respectively. First row shows extraordinarily higher EGF expression across groups with highest level observed at G4. For REGF, no staining signals of expression in G1 and G2. G4 had higher expression. For VEGF, remarkably higher expressions are visible in G3 and G4. Third row represents the expression of PCNA with G3 and G4 demonstrating higher expressions than the other groups.

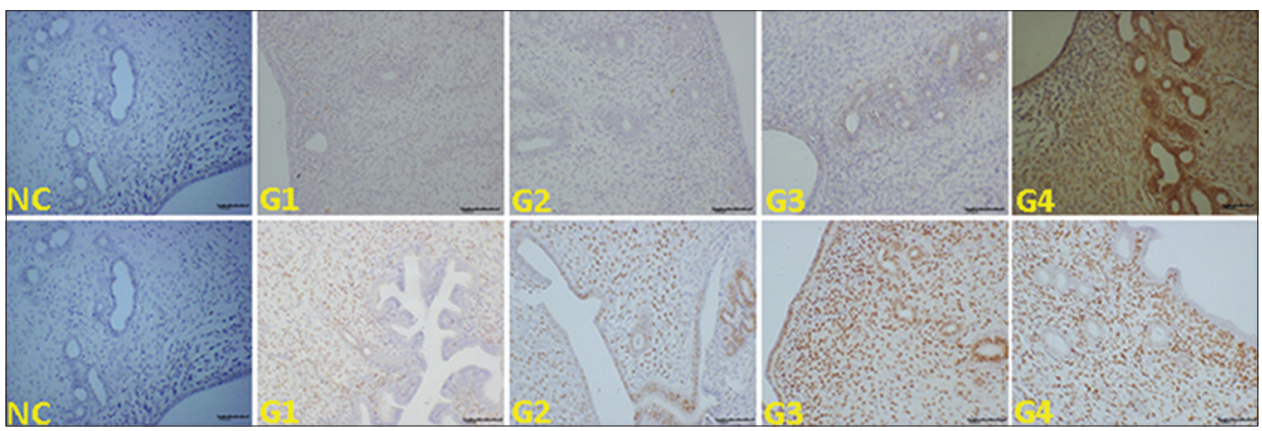

Figure-6: Photomicrograph sections of rat uteri of different experimental groups (G1, G2, G3, and G4). No staining for estrogen receptor was observed in $\mathrm{G} 1$ and $\mathrm{G} 2$ and show higher expression in G4. Second row shows higher expression of $\mathrm{P}_{4} \mathrm{R}$ in G3 and G4 (200x). Negative control (NC) represents control stain without antibody and immunity reaction.

protected against hydroxyl radicals that cause in vitro cytotoxicity on human lung cells and cellular damage from human liver carcinoma [19].
Histologically, the uterine cells and glands of rats showed increased activity when treated with EBN. Furthermore, PCNA density increased, which is a sign 


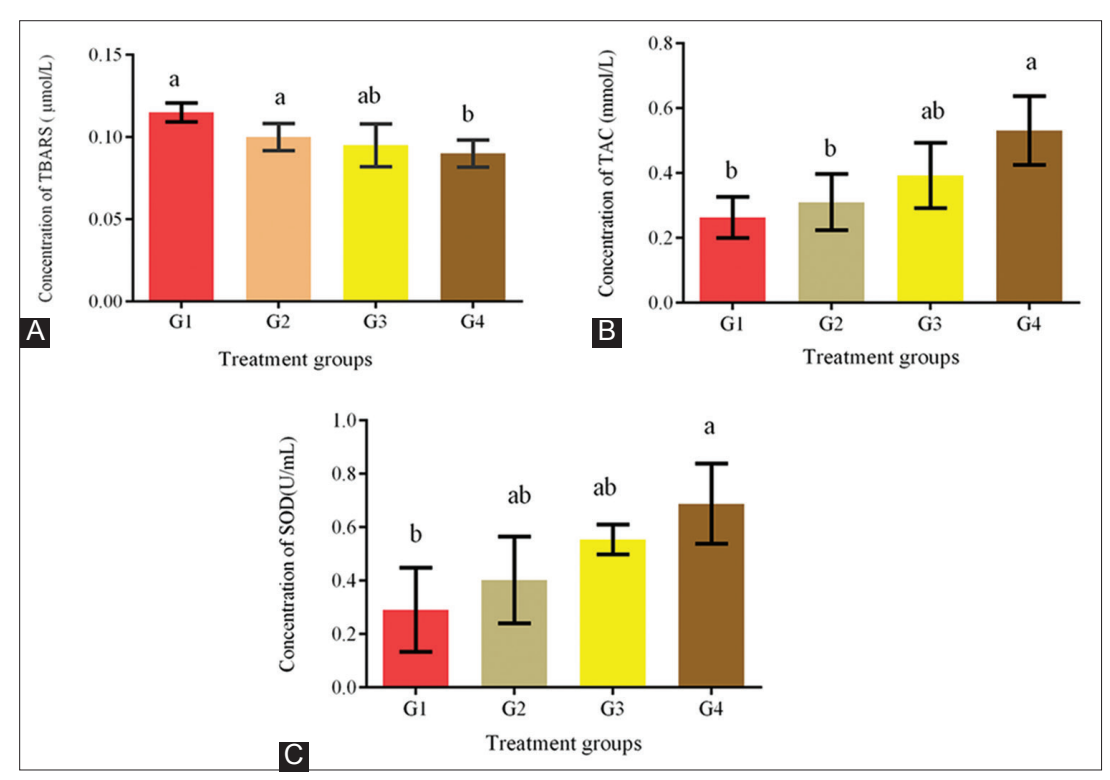

Figure-7: $(A-C)$ Effect of edible bird's nest on oxidative stress and antioxidant biomarkers in plasma. TBARS=Thiobarbituric acid reactive substance, $\mathrm{TAC}=$ Total antioxidant capacity, $\mathrm{SOD}=$ Superoxide dismutase. Data are expressed as means \pm standard error. Different letters $a$ and $b$ within rows denotes significant difference at $p<0.05$. G1=Control, G2=EBN (30 mg/kg body weight); G3=EBN (60 mg/kg body weight); G4=EBN (120 mg/kg body weight).

of DNA synthesis and cell proliferation. These results provide additional evidence to the potential role of EBN in reproduction and fertility. EGF and REGF, VEGF, and interleukine-6 play essential roles in cellular processes and are intercellular mediators that control growth, survival, and cellular differentiation, and function $[20,21]$. This notion agrees with our present results, where the significant expression of EGF and REGF was associated with the abundant proliferation of LE, GE, and uterine glands and the thickening of endothelium. Similar to the study of Roh et al. [22], the current study confirmed that EBN enhances EGF, REGF, VEGF, and PCNA expression in the GE, USE, and uterine stromal cells, thereby indicating the proliferative effect of EBN. Moreover, VEGF is an angiogenic factor in the endometrium and hence is vital to the development, maintenance, and degradation of the structure. VEGF is also a major factor for intensifying the vascularization of uterine glands and stromal cells and thus improves nutrient supply. The link between increased VEGF expression and EBN supplementation reveals how EBN promotes the proliferation of stromal cells, LE, and GE. VEGF is related to the actions of $\mathrm{LH}$ and angiopoietin produced in luteinizing cells [23-25]. Alterations in the hypothalamic-pituitary-gonadal axis affect the induction of steroidogenesis in the interstitial and theca cells of the ovary [26]. The present data suggested that PCNA was influenced by steroidal activity, and $\mathrm{E}_{2} \mathrm{R}$ and $\mathrm{P}_{4} \mathrm{R}$ increase PCNA production. Therefore, we deduce that EBN upregulates the PCNA expression in the uterus.

Estrogen and progesterone essentially affect the uterus through $\mathrm{E}_{2} \mathrm{R}$ and $\mathrm{P}_{4} \mathrm{R}$ [26]. Progesterone is essential for maintaining the stromal and glandular cells of the endometrium and the cells of the myometrium. This hormone also helps uphold implantation and pregnancy in all mammals. Estrogen plays an important role in the proliferation of uterine epithelia and enhances progesterone action by stimulating the PR. This study showed that the increased density of stromal cells, GE, and LE was accompanied by the significant expression of steroid receptors $\left(E_{2} R\right.$ and $\left.P_{4} R\right)$ associated with EBN supplementation. This result provides further evidence on the importance and action mechanism of EBN supplementation in enhancing reproduction.

In this study, EBN was apparently related to the increase in reproductive hormonal expressions of their receptors; this association points to the great effect of the EBN on rat uteri that is yet to be elucidated. Uterine $\mathrm{E}_{2} \mathrm{R}$ expression and uterine $\mathrm{P}_{4} \mathrm{R}$ expression were augmented in a dose-dependent manner and revealed the positive effect of EBN on steroid hormone production. This result agrees with that of Ismail et al. [4], who reported the increased serum $\mathrm{E}_{2}$ levels of ovariectomized rats fed on EBN dietary supplement and hence concluded that EBN can be used as estrogen therapy for ovariectomized-induced aging-related memory loss. Guzeloglu-Kayisli et al. [1] proposed the ovaries, along with the uterus and mammary glands, as the target organs of estrogen and progesterone.

In this study, EBN significantly lowered the TBARS levels $(p<0.05)$ in the treatment groups as compared with those in the untreated control; however, the difference was only significant in G4. AO status was higher $(p<0.05)$ in the treatment groups than in the control group. This finding is similar to those of a previous study, where EBN protein hydrolysates exhibit potent AO activity that lowers OSB levels [19,27].

\section{Conclusion}

The present findings suggested that EBN supplementation could be used to enhance reproduction and 
uterine functions by increasing the proliferation of uterine structures, such as LE, GE, and stromal cells. EBN can also enhance AO activity, and upregulate the expression of EGF, REGF, and VEGF, PCNA, and steroid receptors on uteri.

\section{Authors' Contributions}

This study was intellectualized by AAA, NY, MZAZ, AWH, RY, MAA, and BHA. The investigations were performed by AAA, MAA, and BHA under the supervision of NY, MZAZ, AWH, and RY. Statistical analysis was carried out by AAA and NY. Original manuscript was written by AAA, reviews and editing werefinalized by AAA, NY, MZAZ, AWH, RY, MAA, and BHA. The final manuscript was read and approved by all authors.

\section{Acknowledgments}

The authors would like to thank UPM for providing the fund for this project (Grant Putra IPS/9487100) and also Prof. Abdul Salam Babji, for generously providing the edible bird's nest.

\section{Competing Interests}

The authors declare that they have no competing interests.

\section{References}

1. Guzeloglu-Kayisli, O., Kayisli, U.M. and Taylor, H.S (2009) The role of growth factors and cytokines during implantation: Endocrine and paracrine interactions. Semin. Reprod. Med., 27(1): 62-79.

2. Carpenter, K.D. and Korach, K.S. (2006) Potential biological functions emerging from the different estrogen receptors. Ann. N. Y. Acad. Sci., 1092: 361-373.

3. Bergemann, N., Mundt, C., Parzer, P., Jannakos, I., Nagl, I., Salbach, B., Klinga, K., Runnebaum, B. and Resch, F. (2005) Plasma concentrations of estradiol in women suffering from schizophrenia treated with conventional versus atypical antipsychotics. Schizophr. Res., 73(2-3): 357-366.

4. Ismail, M., Hou, Z.P., Stanslas, J., Iman, M.U., Zhang, Y.D., Ideris, A. and Mahmud, R. (2014) Edible Bird's Nest Pretreatment Prevents Ovariectomy Induced Cognitive Aging in Morris Water Maze. Proceedings of the Edible Bird Nest Industry Conference, November 2014. Putrajaya, Malaysia. p25-26.

5. Matsukawa, N., Matsumoto, M., Bukawa, W., Chiji, H., Nakayama, K., Hara, H. and Tsukahara, T. (2011) Improvement of bone strength and dermal thickness due to dietary edible bird's nest extract in ovariectomized rats. Biosci. Biotechnol. Biochem., 75(3): 590-592.

6. Thavamanithevi, S., Sarifah, R., Lim, C.G., Theanmalar, M., Aidawati, M.S., Devi, M.D. and Saleha, AA. (2014) Characterization and Standardization of Edible Birds Nest (EBN)-Determination of Sialic Acid. Proceedings of the Edible Bird Nest Industry Conference. November 2014, Putrajaya. p25-26.

7. Kong, Y.C., Keung, W.M., Yip, T.T., Ko, K.M., Tsao, S.W. and Ng, M.H. (1987) Evidence that epidermal growth factor is present in swiftlet's (Collocalia) nest. Comp. Biochem. Physiol. Part B. Biochem. Mol. Biol., 87B(2): 221-226.

8. Ng, M.H., Chan, K.H. and Kong, Y.C. (1986) Potentiation of mitogenic response by extracts of the swiftlet's (Collocalia) nest. Biochem. Int., 13(3): 521-531.

9. Kong, Y.C., Tsao, S.W., Song, M.E., Ng, M.H. and Zhefu, L. (1989) Potentiation of mitogenic response by extracts of the swiftlet's (Apus) nest collected fuuuj7rom Huai-Ji. Acta Zoolog. Sin., 35(4): 429-435

10. Gheri, G., Vichi, D., Thyrion, G.D., Bonaccini, L., Vannelli, G.B., Marini, M. and Sgambati, E. (2009) Sialic acid in human testis and changes with aging. Reprod. Fertil. Dev., 21(5): 625-633.

11. Sen, S., Chowdhury, G. and Chowdhury, M. (2001), Sialic acid binding protein of human endometrium: Its regulation by steroids. Mol. Cell. Biochem., 221(1-2): 17-23.

12. Pallares, P. and Gonzalez-Bulnes, A. (2009) A new method for induction and synchronization of oestrus and fertile ovulations in mice by using exogenous hormones. Lab. Anim., 43: 295-299.

13. Muhammad, S.I., Ismail, M., Mahmud, R.B., Salisu. A.M. and Zakaria, Z.A. (2013) Germinated brown rice and its bioactive modulate the activity of uterine cells in oophorectomies rats as evidenced by gross cytohistological and immunohistochemical changes. BMC Complement. Altern Med., 13: 198.

14. Panzan, M.Q., Mattar, R., Maganhin, C.C., dos Santos, S.R., Rossi, A.G.Z., da Motta, E.L.A., Baracat, E.C. and Soares, J.M. Jr. (2013) Evaluation of FAS and caspase-3 in the endometrial tissue of patients with idiopathic infertility and recurrent pregnancy loss. Eur. J. Obstet. Gynecol. Reprod. Biol., 167(1): 47-52.

15. Schmidt, C.M., Blount, J.D. and Bennett, N.C. (2014) Reproduction is associated with a tissue-dependent reduction of oxidative stress in eusocial female damaraland molerats (Fukomys damarensis). PLoS One, 9(7): e103286.

16. Yida, Z., Imam, M.U., Ismail, M., Hou, Z., Abdullah, M.A., Ideris, A. and Ismail, N. (2015) Edible bird's nest attenuates high fat diet-induced oxidative stress and inflammation via regulation of hepatic antioxidant and inflammatory genes. BMC Complement. Altern. Med., 15(1): 310.

17. Zucchetto, A., Serraino, D., Polesel, J., Negri, E., De Paoli, A., Dal Maso, L., Montella, M., La Vecchia, C. and Franceschi, S. (2009) Hormone-related factors and gynecological conditions in relation to endometrial cancer risk. Eur. J. Cancer Prev., 18(4): 316-321.

18. Gray, C., Burghardt, R., Johnson, G., Bazer, F. and Spencer, T. (2002) Evidence that absence of endometrial gland secretions in uterine gland knockout ewes compromises conceptus survival and elongation. Reproduction, 124: $289-300$.

19. Ghassem, M., Arihara, K., Mohammadi, S., Sani, N.A. and Babji, A.S. (2017) Identification of two novel antioxidant peptides from edible bird's nest (Aerodramus fuciphagus) protein hydrolysates. Food Funct., 8(5): 2046-2052.

20. Hirano, T., Ishihara, K. and Hibi, M. (2000) Roles of STAT3 in mediating the cell growth, differentiation and survival signals relayed through the IL-6 family of cytokine receptors. Oncogene, 19: 2548.

21. Alan, E., Liman, N. and Sağsöz, H. (2015) The profile of the epidermal growth factor system in rat endometrium during postpartum involution period. Vet. Res. Commun., 39: $115-135$.

22. Roh, K.B., Lee, J., Kim, Y.S., Park, J., Kim, J.H., Lee, J. and Park, D. (2011) Mechanisms of edible bird's nest extract-induced proliferation of human adipose-derived stem cells. Evid. Based Complement. Altern Med., 2012: 797520.

23. Christenson, L.K. and Stouffer, R.L. (1997) Folliclestimulating hormone and luteinizing hormone/chorionic gonadotropin stimulation of vascular endothelial growth factor production by macaque granulosa cells from pre-and periovulatory follicles 1. J. Clin. Endocrinol. Metab., 82(7): 2135-2142.

24. Anasti, J., Kalantaridou, S., Kimzey, L., George, M. and Nelson, L. (1998) Human follicle fluid vascular endothelial growth factor concentrations are correlated with luteinization in spontaneously developing follicles. Human Reprod., 13: 1144-1147.

25. Dickson, S.E. and Fraser, H.M. (2000) Inhibition of early 
luteal angiogenesis by gonadotropin-releasing hormone antagonist treatment in the primate. J. Clin. Endocrinol. Metab., 85(6): 2339-2344.

26. Kakuta, H., Tanaka, M., Chambon, P., Watanabe, H., Iguchi, T. and Sato, T. (2012) Involvement of gonadotropins in the induction of hypertrophy-hyperplasia in the interstitial tissues of ovaries in neonatally diethylstilbestrol-treated mice. Reprod. Toxicol., 33(1): 35-44.

27. Zhiping, H., Imam, M.U., Ismail, M., Ismail, N., Yida, Z., Ideris, A., Sarega, N. and Mahmud, R. (2015) Effects of edible bird's nest on hippocampal and cortical neurodegeneration in ovariectomized rats. Food Funct. 6: 1701-1711.

$* * * * * * * *$ 